\title{
Evaluation of solubility and partition properties of ampicillin-based ionic liquids
}

\author{
Catarina Florindo, João M.M. Araújo, Filipa Alves, Carla Matos, Ricardo Ferraz, \\ Cristina Prudêncio, João Paulo Noronha, Željko Petrovski, Luís Branco, \\ Luís Paulo N. Rebelo, Isabel M. Marrucho
}

\author{
A B S T R A C T
}

In order to overcome the problems associated with low water solubility, and consequently low bioavailability of active pharmaceutical ingredients (APIs), herein we explore a modular ionic liquid synthetic strategy for improved APIs. Ionic liquids containing L-ampicillin as active pharmaceutical ingredient anion were prepared using the methodology developed in our previous work, using organic cations selected from substituted ammonium, phosphonium, pyridinium and methylimidazolium salts, with the intent of enhancing the solubility and bioavailability of L-ampicillin forms. In order to evaluate important properties of the synthesized API-ILs, the water solubility at $25^{\circ} \mathrm{C}$ and $37{ }^{\circ} \mathrm{C}$ (body temperature) as well as octanol-water partition coefficients $\left(K_{\text {ow }}\right.$ 's) and HDPC micelles partition at $25^{\circ} \mathrm{C}$ were measured. Critical micelle concentrations (CMC's) in water at $25^{\circ} \mathrm{C}$ and $37^{\circ} \mathrm{C}$ of the pharmaceutical ionic liquids bearing cations with surfactant properties were also determined from ionic conductivity measurements.

Keywords:

Active pharmaceutical ionic liquids

Solubility

Bioavailability

Octanol-water partition coefficients

Critical micelle concentrations

\section{Introduction}

Ionic liquids (ILs) are organic salts with a melting point, by definition, below $100^{\circ} \mathrm{C}$ (some of them are liquids at room temperature) (Rogers and Seddon, 2005). ILs can present a different structural organization according the suitable combination of various organic cations and anions of organic or inorganic nature, allowing a great variety of tuneable interactions and subsequent applications, particularly in the areas of chemical, biotechnology, and pharmaceutical industry (Wasserscheid and Welton, 2002). ILs build up a unique synthetic architectural platform on which the properties of both cation and anion components can be independently modified, while retaining the essential desirable features of the IL state of matter (Smiglak et al., 2006). An IL approach has the appropriate features in the design of active pharmaceutical ingredients (APIs), where a fragile balance exists between the exact chemical functionality needed for the desired effect, in the absence of adverse side effects, and the physical properties required for manufacturing and transport, chemical stability, solubility and bioavailability (Bennett and Cole, 2003; Byrn et al., 1999).

The combination of APIs with specific counter-ions capable of lowering their melting point to below room temperature has been reported in recent publications. One approach taken is to pair an active ion with a counter-ion which is a known excipient (Alves et al., 2013; Bica et al., 2012). For example, the IL propantheline acesulfamate contains the active cation from the API propantheline bromide (an antimuscurinic used to treat a number of conditions such as excessive sweating, cramps, spasms of the stomach, etc.) 
with acesulfamate, a known artificial sweetener and a pharmaceutical additive (Dean et al., 2009).

The first attempt to specifically prepare active pharmaceutical ionic liquids (API-ILs) was accomplished by Rogers and co-workers (Hough et al., 2007), who developed the potential scope of this poorly exploited drug phase. Since then, API-ILs have been studied by a number of groups. Bica and co-workers studied ILs based on analgesic, anti-pyretic and anti-inflammatory compounds (acetylsalicylic and salicylic acids) (Bica et al., 2010). Hough et al. (Hough-Troutman et al., 2009) and MacFarlane et al. (Dean et al., 2009) reported API-ILs containing various active cations/anions, while Cybulski and co-workers (Cybulski et al., 2011) prepared ILs based on antiseptic/disinfectant cations and enzyme/amino acids anions, which were found to be very effective against bacteria and fungi.

These API-ILs compounds offer improved properties, such as increased stability, solubility, permeability and drug delivery, as compared to the corresponding solid pharmaceutical forms (Ferraz et al., 2012). Also, the use of an active drug in the liquid form (at room temperature) can avoid some of the issues of polymorphism associated with crystalline solids and, thus, dramatically influence the drug's solubility and dosages (Bica et al., 2010; Ferraz et al., 2011; Stoimenovski et al., 2010). The use of this modular ionic liquids-based strategy to produce tuneable active pharmaceutical ingredients is very attractive since it allows infinite new possibilities, challenges and opportunities. Besides the elimination of polymorphism and the adjustable solubility, the question of how ionic liquids conjugated with pharmaceutical ingredients could enhance the transport across the membrane is of interest within the APIs context (Dean et al., 2009; Stoimenovski and MacFarlane, 2011; Stoimenovski et al., 2010; Variankaval et al., 2008).

One of the most recent studies concerning API-ILs refers to the development of novel ionic liquids based on L-ampicillin (Ferraz et al., 2012), where ampicillin was used as anion combined with different organic cations. In that work, we reported a new and efficient method for the synthesis of $\beta$-lactam antibiotics like ampicillin, which may prove useful for the development of new bioactive materials or to reduce drug resistance in microorganisms. This study is a continuation of our previous work (Ferraz et al., 2012), and it aims at evaluating the effect of the proposed methodology on two important parameters within drug absorption: water solubility and hydrophilic/lipophilic balance. This last parameter represents the delicate balance between the different thermophysical properties and influences the bioavailability of a drug, as well as its toxicity and half-life features. The octanol-water partition coefficient $\left(K_{\mathrm{ow}}\right.$ 's) is the classic method to access hydrophilic/lipophilic balance (Hansch and Dunn, 1972; Leo et al., 1971) and it is the most used parameter in drug development quantitative structureactivity relationship models. However, the isotropic nature of octanol makes it a poor mimetic system for biomembranes. More structured membrane models, such as hexadecylphosphocholine (HDPC) micelles, are more efficient to emulate the ionic, H-bond and dipole-dipole interactions that can occur between the drug and the membrane (Ferreira et al., 2005). HDPC as zwitterionic phospholipid molecules possess a positive choline and a negative phosphoryl group close to a hydrophobic core, as presented by membranes phosphatidylcholine, and can be used as a biomimetic model.

In order to evaluate the tuning capacity of the ionic liquids synthetic platform, water solubilities or critical micelle concentrations (CMC's) for the compounds bearing cations with surfactant properties, at $25^{\circ} \mathrm{C}$ and $37^{\circ} \mathrm{C}$ (body temperature), of ampicillinbased ILs and of the starting API, were measured. The study of the combination of an API with an ionic liquid possessing surfactant activity is important because novel therapies using surfactant API-ILs as drug delivery devices can offer interesting avenues to be explored (Bernardes et al., 2011; Hansch and Dunn, 1972; Liu et al., 2006).

The proposed ampicillin-based ILs provide a platform for improved properties, including solubility, dissolution rate, bioavailability, activity, and the possibility to open novel treatment options.

\section{Materials and methods}

\subsection{Materials}

L-Ampicillin ( $\geq 96 \%$ mass fraction purity) and ampicillin sodium salt $(\geq 99 \%$ mass fraction purity) were purchased from Sigma-Aldrich and were used as supplied. Octanol spectrophotometric grade, hexadecylphosphocholine and Hepes were purchased from Sigma-Aldrich and used as supplied. Milli-Q water was used in all experiments throughout the work (conductivity less than $\left.0.1 \mu \mathrm{S} / \mathrm{cm}^{-1}\right)$.

Trihexyl(tetradecyl)phosphonium chloride $\quad\left(\left[\mathrm{P}_{6,6,6,14}\right] \mathrm{Cl}\right.$; $\geq 95 \%$ mass fraction purity) and cetylpyridinium chloride ([ $\left.\mathrm{C}_{16} \mathrm{Pyr}\right] \mathrm{Cl}$; > 98\% mass fraction purity) were supplied by CYTEC Industries and Sigma-Aldrich, respectively. The ionic liquids 1-ethyl-3-methylimidazolium bromide $\left(\left[\mathrm{C}_{2} \mathrm{MIM}\right] \mathrm{Br}\right.$; >98\% mass fraction purity) and 1-hydroxy-ethyl-3-methylimidazolium chloride $\left(\left[\mathrm{C}_{2} \mathrm{OHMIM}\right] \mathrm{Cl}\right.$; $>98 \%$ mass fraction purity) were supplied from Solchemar. Prior to use, all ILs were dried under vacuum. The water content was verified by Karl Fischer titration and no further purification was carried out. The purities of all ILs and salts were proven by ${ }^{1} \mathrm{H}$ NMR analysis.

Six L-ampicillin-based compounds were synthesized according to the methodology proposed in our previous work: four ILs, tetraethylammonium ampicillin ([TEA][Amp]), choline ampicillin ([ $\left.\mathrm{N}_{1112 \mathrm{OH}}\right][$ Amp]), 1-ethyl-3-methylimidazolium ampicillin ([C 2 MIM] [Amp]) and 1-hydroxy-ethyl-3-methylimidazolium ampicillin ([C $\left.\left.\mathrm{C}_{2} \mathrm{OHMIM}\right][\mathrm{Amp}]\right)$, and two salts, trihexyltetradecylphosphonium ampicillin $\left(\left[\mathrm{P}_{6,6,6,14}\right][\mathrm{Amp}]\right)$ and cetylpyridinium ampicillin ([ $\left.\left.\mathrm{C}_{16} \mathrm{Pyr}\right][\mathrm{Amp}]\right)$. Their chemical structure and respective acronym is shown in Table 1. More experimental details on the synthesis can be found in our previous work (Ferraz et al., 2012). The water content of all the API-ILs studied in this work was $<500 \mathrm{ppm}$.

All API-ILs were completely characterized by ${ }^{1} \mathrm{H}$ and ${ }^{13} \mathrm{C}$ NMR, FTIR, and ESI mass spectra in order to check their expected structures and final purities. The quantitative integration of the API-ILs characteristic ${ }^{1} \mathrm{H}$ NMR resonance peaks confirmed the expected cation/anion ratios. All characterization details of the ampicillinbased ILs are appended in Supporting Information.

\subsection{Water solubility}

In order to determine the solubility of ampicillin-based ionic liquids and ampicillin, samples were prepared by adding an excess amount of compound to Milli-Q water in vials of $1.5 \mathrm{~mL}$. Subsequently to the preparation of saturated solutions, vials were placed in a Thermomixer Comfort (eppendorf $1.5 \mathrm{~mL}$ ) for different time frames, kept under vigorous stirring at $1400 \mathrm{rpm}$ and controlled temperature at $25^{\circ} \mathrm{C}$ and $37^{\circ} \mathrm{C}\left( \pm 0.1^{\circ} \mathrm{C}\right)$. At fixed times vials were collected and centrifuged in a Biofuge 28 RS, Heraeus Sepatech, for $5 \mathrm{~min}$ at $14,000 \mathrm{rpm}$, to enhance physical separation of the two phases and to ensure no sampling contamination. Following, samples were analyzed until no significant discrepancies in the solubility values were verified. The quantification of the ampicillin-based ILs and L-ampicillin were accomplished by UV-vis spectroscopy using a Shimadzu model UV-1800 - PharmaSpec spectrophotometer, with quartz cells at a wavelength of $257 \mathrm{~nm}$, which is the wavelength of the maximum absorbance of 
Table 1

Chemical structure and respective acronym of ionic liquids containing L-ampicillin as active pharmaceutical ingredient anion considered in the present study.

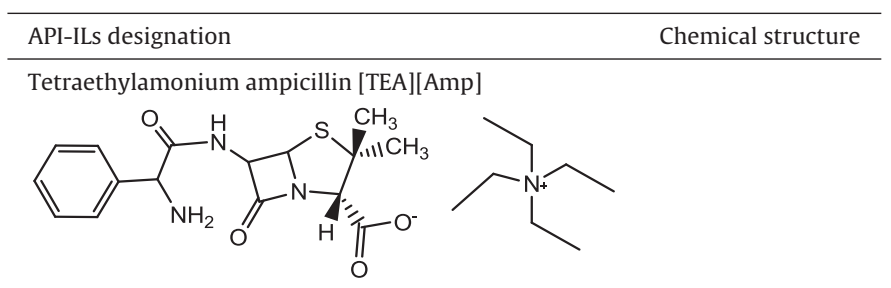

Choline ampicillin $\left[\mathrm{N}_{1112 \mathrm{OH}}\right][$ Amp $]$

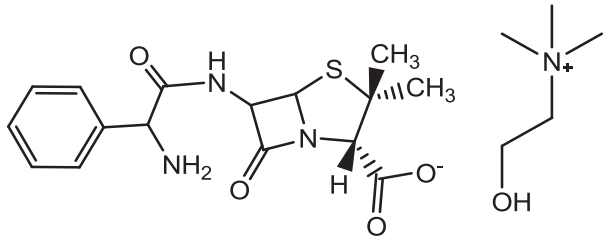

1-Ethyl-3-methylimidazolium ampicillin [ $\left.\mathrm{C}_{2} \mathrm{MIM}\right][\mathrm{Amp}]$

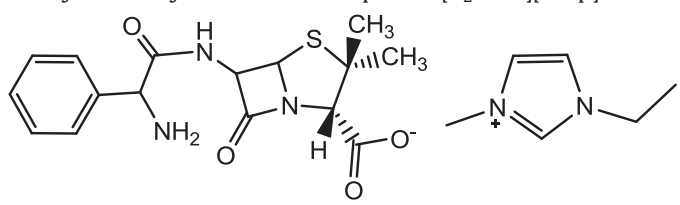

1-Hydroxy-ethyl-3-methylimidazolium ampicillin [ $\left.\mathrm{C}_{2} \mathrm{OHMIM}\right][\mathrm{Amp}]$

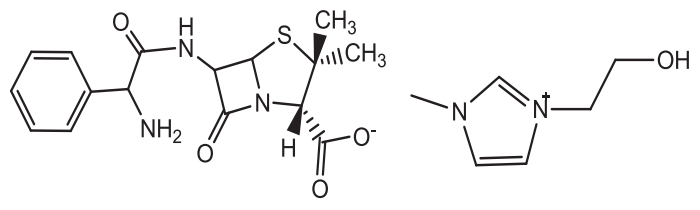

Cetylpyridinium ampicillin [ $\left.\mathrm{C}_{16} \mathrm{Pyr}\right][\mathrm{Amp}]$

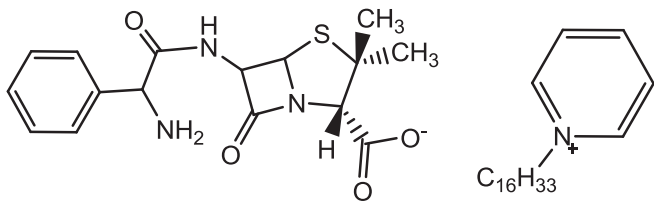

Trihexyltetradecylphosphonium ampicillin $\left[\mathrm{P}_{6,6,6,14}\right][$ Amp $]$

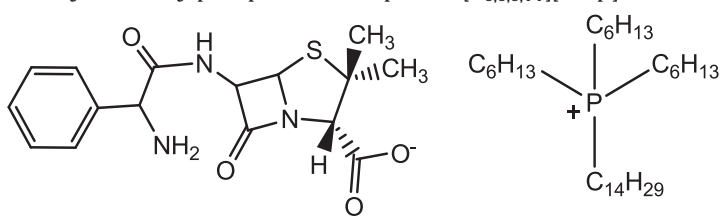

L-ampicillin in water. Triplicates were always measured. A calibration curve was previously established for L-ampicillin and ampicillin-based ionic liquids in Milli-Q water (for all curves $\left.R^{2}>0.9957\right)$.

\subsection{Octanol-water partition coefficients}

The octanol-water partition coefficients of L-ampicillin and ampicillin-based ILs were determined by the shake-flask method, described in the OECD guidelines. This method requires that the solvents, water and n-octanol, need to be previously mutually saturated. Then, a solution was prepared through the complete dissolution of the solute, L-ampicillin and ampicillin-based ILs, in a vial containing water saturated in n-octanol. Approximately $4 \mathrm{~mL}$ of this solution was added to a vial containing a magnetic stir bar and the same volume of water saturated with n-octanol was added. This vial was then vigorously stirred for approximately $1 \mathrm{~h}$ at a constant temperature $25^{\circ} \mathrm{C}$, which was found to be the adequate amount of time for the equilibrium to be reached. Sampling of both phases was performed by careful use of syringes. The syringe used to collect the water-rich phase had been filled with air, which was expelled slowly while passing through the octanol phase. Subsequently, both samples were centrifuged for $1 \mathrm{~h}$ at $3750 \mathrm{rpm}$ and $25^{\circ} \mathrm{C}$ in order to ensure the complete phase separation. After that, both phases were isolated and the concentrations were determined using the UV spectrophotometer at the characteristic wavelength of L-ampicillin $(257 \mathrm{~nm})$. The calibration curves for each one of the phases was previously done using standards of different known concentrations of the compounds in water saturated octanol or in octanol saturated water. In order to evaluate the dependence of the $K_{\mathrm{ow}}$ 's on the starting compound concentration, the initial concentration of L-ampicillin and ampicillin-based ionic liquids in water-rich phase was varied from approximately 0.6 to $1.3 \mathrm{mmol} \mathrm{L}^{-1}$. Triplicates were always measured in the $K_{\mathrm{ow}}$ experiments.

\subsection{HDPC-water partition coefficients}

For the determination of the HDPC-water partition coefficients $\left(K_{\mathrm{p}}\right)$, solutions were prepared with $10 \mathrm{mM}$ Hepes buffer $(\mathrm{pH} 7.4)$, being the ionic strength adjusted to $0.1 \mathrm{~mol} \mathrm{~L}^{-1}$ with $\mathrm{NaCl}$. For all solutions Milli-Q water was used. A HDPC stock solution prepared extemporaneously $\left(4 \mathrm{mmol} \mathrm{L}^{-1}\right)$ was diluted to prepare a set of solutions with different HDPC concentrations (ranging from 0 to ca. $2 \mathrm{mmol} \mathrm{L}^{-1}$ ), in which the drug concentration was kept constant (around $150 \mu \mathrm{mol} \mathrm{L}^{-1}$ ). A set of "blank" suspensions (with no added drug) was prepared. All solutions were left $4 \mathrm{~h}$ in the dark, at room temperature (approx. $25^{\circ} \mathrm{C}$ ), to incubate. The spectra of all solutions were collected in a double-beam spectrophotometer (Perkin Elmer, Lambda 25), equipped with UV WinLab V2.85 software for data acquisition, with Hepes buffer as reference sample, at room temperature. Wavelength interval, scanning rate, and light path were $1 \mathrm{~nm}, 240 \mathrm{~nm} / \mathrm{min}$, and $1 \mathrm{~cm}$, respectively. The second derivative spectra were calculated for the samples and blanks after spectra smoothing, by the use of Origin 8.5 , using 12 points in the derivative calculus. The HDPC-water partition coefficients were determined by performing a non-linear fitting of the proposed mathematical model (Castro et al., 2001; Marcelino et al., 2007) to the experimental data using the same computer program. Three independent experiments were conducted for each drug under analysis.

\subsection{Critical micelle concentration}

The critical micelle concentrations of the ampicillin-based compounds with cations bearing surfactant properties were calculated using ionic conductivity measurements. A CDM210 Radiometer Analytical conductimeter was used to measure the ionic conductivities $(\mu \mathrm{S} / \mathrm{cm})$ of surfactant solutions, in a glass cell containing a magnetic stirrer. In order to ensure the temperature control, a jacketed cell was used with a water bath controlled to $\pm 0.01^{\circ} \mathrm{C}$. The cell temperature was measured by means of a PT100 platinum resistance sensor coupled to a Keithly 199 System DMM/Scanner.

The probe was previously calibrated against high accuracy mercury thermometers at different temperatures. In this method, a known amount of Milli-Q water was placed in a thermostated glass cell, at $25^{\circ} \mathrm{C}$ and $37^{\circ} \mathrm{C}$, and the surfactant solution of known concentration was progressively added using a syringe. After each addition, the mixture was stirred to obtain a homogeneous solution, and the ionic conductivity was measured. Each conductivity value was measured at least three times. The methodology adopted was validated through the determination of the CMC values of cetylpyridinium chloride $\left(\left[\mathrm{C}_{16} \mathrm{Pyr}\right] \mathrm{Cl}\right)$ and trihexyltetradecylphosphonium chloride $\left(\left[\mathrm{P}_{6,6,6,14}\right] \mathrm{Cl}\right)$. 


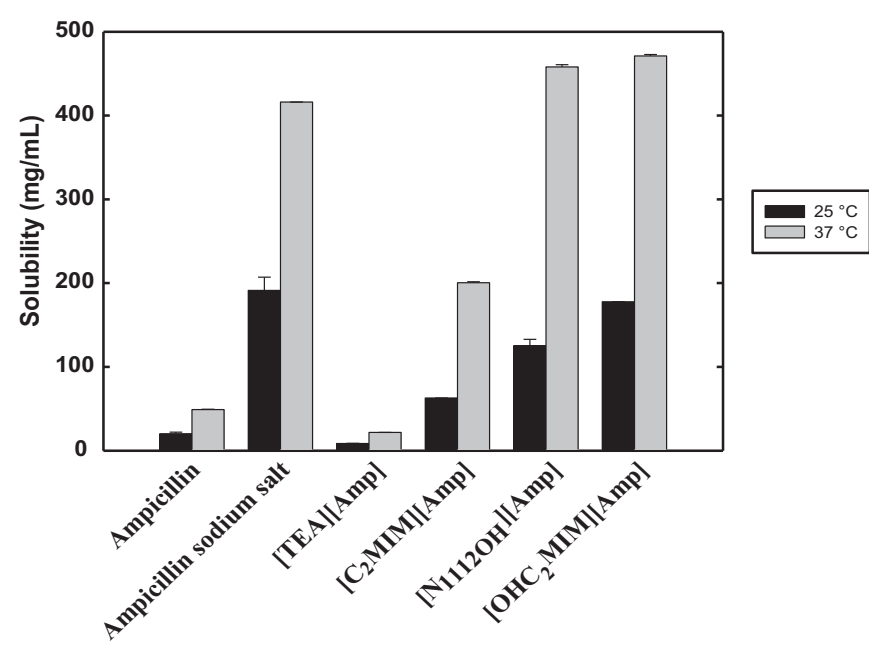

Fig. 1. Solubility of L-ampicillin, ampicillin sodium salt and ampicillin-based ILs in water at $25^{\circ} \mathrm{C}$ and $37^{\circ} \mathrm{C}$.

\section{Results and discussion}

\subsection{Water solubility and octanol-water partition coefficient}

The study of the solubility and the partition coefficient of pharmaceuticals is essential in order to predict their absorption in the different parts of the human body. If not efficiently absorbed, the ideal plasmatic concentration is not reached and consequently the therapeutic effect of the API will not be obtained.

The solubilities of the ampicillin-based ILs, as well as the starting L-ampicillin and ampicillin sodium salt, in water at $25^{\circ} \mathrm{C}$ and $37^{\circ} \mathrm{C}$, are listed in Table 2 , together with literature values. Only one value for the solubility of the acid form of ampicillin at $25^{\circ} \mathrm{C}$ and $p=1 \mathrm{~atm}$ was found in the open literature (Liu et al., 2006). The value published by Liu et al. (2006), $10.8 \mathrm{mg} / \mathrm{mL}$, is quite different from that obtained in this work, $20.26 \mathrm{mg} / \mathrm{mL}$. However, Liu et al. (2006), used a phosphate buffer solution $(0.01 \mathrm{M}), \mathrm{pH}=5.8$, at $25^{\circ} \mathrm{C}$ and the mixture was stirred using a magnetic stir bar for approximately $2 \mathrm{~h}$. Therefore, it is acceptable that their value is quite different from that presented in this work. It should also be mentioned that the evolution of the quantity of ampicillin in the aqueous solution with time was checked through our measurements to ensure that the equilibrium was reached. Also, for the ampicillin sodium salt the value provided by Sigma-Aldrich $(50 \mathrm{mg} / \mathrm{mL})$ is different from that obtained in the present work, $191.30 \mathrm{mg} / \mathrm{mL}$. This value is only indicative and relates to solubility tests required for market approval. According to the information provided, this compound is completely soluble at $50 \mathrm{mg} / \mathrm{mL}$ concentration in water, which was the composition tested value.

Solubility is affected by many factors, being extrinsic or intrinsic to APIs. Among the extrinsic factors, a relevant parameter evaluated in this work is the influence of temperature. The solubility experiments were performed at $25^{\circ} \mathrm{C}$ and $37^{\circ} \mathrm{C}$ (body temperature). The influence of temperature in the solubility assays can be observed in Fig. 1. For all compounds, L-ampicillin, ampicillin sodium salt and ampicillin-based ILs, solubility always increases with temperature. The solubility values at $37^{\circ} \mathrm{C}$ more than double the values at $25^{\circ} \mathrm{C}$. The analysis of this figure clearly shows the efficacy of using the ionic liquids synthetic platform to tailor the APIs water solubility It is possible to observe that the water solubility of the API-ILs spans over a wide range of values (from 8.59 to $177.80 \mathrm{mg} / \mathrm{mL}$ at $25^{\circ} \mathrm{C}$ ), either lower or much higher than the water solubility measured for L-ampicillin $\left(20.26 \mathrm{mg} / \mathrm{mL}\right.$ at $\left.25^{\circ} \mathrm{C}\right)$. Taking into account that some of these ampicillin forms are in fact salts, we can also establish a comparison with the water solubility of the ampicillin sodium salt
( $191.30 \mathrm{mg} / \mathrm{mL}$ at $25^{\circ} \mathrm{C}$ ), which is the highest of all the ampicillin forms studied in this work. It can be concluded that the appropriate choice of the counter ion, cation in this case, allows the fine tuning of aqueous solubility of the starting ampicillin API.

The water solubility values for the ampicillin-based ILs (Fig. 1 and Table 2) decreases, for both temperatures, accordingly to the sequence: $\left[\mathrm{C}_{2} \mathrm{OHMIM}\right][\mathrm{Amp}]>\left[\mathrm{N}_{1112 \mathrm{OH}}\right][$ Amp $]>$ $\left[\mathrm{C}_{2} \mathrm{MIM}\right][\mathrm{Amp}]>[\mathrm{TEA}][\mathrm{Amp}]$. These results can be interpreted taking into account the chemical structure of the cations since, these four ionic liquids belong to two distinct families, imidazoliums and ammoniums. The most hydrophilic ILs cations are those bearing the $\mathrm{OH}$ group in the alkyl chains, [ $\left.\mathrm{C}_{2} \mathrm{OHMIM}\right][\mathrm{Amp}]$ and $\left[\mathrm{N}_{1112 \mathrm{OH}}\right][$ Amp]. The introduction of this group obviously enhances the polarity and the hydrogen bonding capacity of the cation, which is translated in an increase of the water solubility of the respective ampicillin-based ILs when compared to the other two parent cations based ILs, [ $\left.\mathrm{C}_{2} \mathrm{MIM}\right][\mathrm{Amp}]$ and [TEA][Amp]. For the imidazolium-based ILs ([C $\left.\mathrm{C}_{2} \mathrm{OHMIM}\right][\mathrm{Amp}]$ and $\left.\left[\mathrm{C}_{2} \mathrm{MIM}\right][\mathrm{Amp}]\right)$, the effect of the introduction of the $\mathrm{OH}$ group in the cation alkyl side-chain on the API-ILs aqueous solubility is an almost 3-fold increase, from $62.90 \mathrm{mg} / \mathrm{mL}$ for $\left[\mathrm{C}_{2} \mathrm{MIM}\right][\mathrm{Amp}]$ to $177.80 \mathrm{mg} / \mathrm{mL}$ for $\left[\mathrm{C}_{2} \mathrm{OHMIM}\right][\mathrm{Amp}]$. In the case of the ammonium-based ionic liquids ([N $\left.\mathrm{N}_{1112 \mathrm{OH}}\right][\mathrm{Amp}]$ and [TEA][Amp]), two factors contribute to the almost 15-fold increase of the aqueous solubility when comparing tetraethylammonium cation $\left([\mathrm{TEA}]^{+}\right.$) with choline cation $\left(\left[\mathrm{N}_{1112 \mathrm{OH}}\right]^{+}\right), 8.59 \mathrm{mg} / \mathrm{mL}$ and $125.30 \mathrm{mg} / \mathrm{mL}$, respectively; First, the increase of hydrophilicity of the $\left[\mathrm{N}_{1112 \mathrm{OH}}\right]^{+}$cation by the introduction of the $\mathrm{OH}$ group on the cation alkyl side-chain, and second the increase of hydrophobicity of the [TEA $]^{+}$cation by the increment of the length of the alkyl side-chains (check Table 1 for the chemical structures).

Another interesting point to be noticed is that for the compounds studied, bearing or not the $\mathrm{OH}$ group, the imidazoliumbased ionic liquids are more hydrophilic than ammonium-based ones. This fact can probably be attributed to the more exposed charge of imidazolium cation when compared to that of the tetraalkylammonium cation, where the charge is more hidden due to the presence of four hydrocarbon chains as well as the presence of an acidic proton $\mathrm{H}-2$ from imidazolium cation. These structural differences in terms of the charge accessibility have already been observed by molecular dynamics and used to interpret other phenomena (Blesic et al., 2010; Costa et al., 2012; Marcelino et al., 2007).

Taking into account that the proposed ampicillin-based ILs belong to the "special class" of salts, ionic liquids, and that in the pharmaceutical industry the salt formation approach is commonly used to increase the solubility and the dissolution rate of ionizable drugs, we also measured the water solubility of ampicillin sodium salt at both temperatures $\left(25^{\circ} \mathrm{C}\right.$ and $\left.37^{\circ} \mathrm{C}\right)$. Curiously, the aqueous solubility data of ampicillin sodium salt and the ampicillinbased ILs [ $\mathrm{C}_{2} \mathrm{OHMIM]}[\mathrm{Amp}]$ and $\left[\mathrm{N}_{1112 \mathrm{OH}}\right][$ Amp] are of the same order of magnitude for both temperatures (Fig. 1 and Table 2). From the aqueous solubility data, depicted in Fig. 1 and Table 2, it can be affirmed that the proposed methodology, based on IL platform, is efficient concerning the tailoring of L-ampicillin water solubility. These results demonstrate the ease of water solubility manipulation, an important factor in drug delivery approaches (Stoimenovski et al., 2012).

In toxicology and pharmacology the octanol-water partition coefficient is used as a simplified model to mimic blood/lipidic membrane partition. It has become an essential tool for the understanding of the tendency of a chemical to cross biological membranes. It is an important parameter since it describes the hydrophobic/hydrophilic balance of a compound thus assessing in a simple way, the transport of an API in the distribution and its affinity for cell membranes (Hansch and Dunn, 1972; Leo et al., 1971; 
Table 2

Solubility of L-ampicillin, ampicillin sodium salt and ampicillin-based ILs (mean and standard deviation), in water at $25^{\circ} \mathrm{C}$ and $37^{\circ} \mathrm{C}$.

\begin{tabular}{|c|c|c|}
\hline APIs/API-ILs & Solubility at $25^{\circ} \mathrm{C}(\mathrm{mg} / \mathrm{mL})$ & Solubility at $37^{\circ} \mathrm{C}(\mathrm{mg} / \mathrm{mL})$ \\
\hline L-Ampicillin & $20.26 \pm 1.78((10.08)($ Liu et al., 2006)) & $49.08 \pm 0.35$ \\
\hline Ampicillin sodium salt & $191.30 \pm 15.80(50.00)^{\mathrm{a}}$ & $416.10 \pm 0.02$ \\
\hline$[\mathrm{TEA}][\mathrm{Amp}]$ & $8.59 \pm 0.21$ & $21.83 \pm 0.02$ \\
\hline$\left[\mathrm{C}_{2} \mathrm{MIM}\right][\mathrm{Amp}]$ & $62.90 \pm 0.02$ & $200.50 \pm 1.10$ \\
\hline$\left[\mathrm{N}_{1112 \mathrm{OH}}\right][$ Amp $]$ & $125.30 \pm 7.60$ & $457.90 \pm 2.70$ \\
\hline$\left[\mathrm{C}_{2}\right.$ OHMIM] $]$ Amp] & $177.80 \pm 0.02$ & $471.10 \pm 1.80$ \\
\hline
\end{tabular}

a Value from Sigma-Aldrich (data sheet number A9518).

Table 3

Octanol-water partition coefficients of L-ampicillin, ampicillin sodium salt and ampicillin-based ILs (mean and standard deviation) at $25^{\circ} \mathrm{C}$, determined by the shake flask method.

\begin{tabular}{ll}
\hline API/API-ILs & $K_{\text {ow }}$ \\
\hline L-Ampicillin & $0.020 \pm 0.001(0.050$ (Hollosy et al., 2006)) \\
Ampicillin sodium salt & $0.068 \pm 0.007$ \\
{$\left[C_{2}\right.$ OHMIM][Amp] } & $0.140 \pm 0.010$ \\
{$\left[\mathrm{~N}_{1112 \mathrm{OH}}\right][\mathrm{Amp}]$} & $0.220 \pm 0.018$ \\
{$\left[\mathrm{C}_{2} \mathrm{MIM}\right][\mathrm{Amp}]$} & $0.300 \pm 0.017$ \\
{$[\mathrm{TEA}][$ Amp] } & $0.310 \pm 0.020$ \\
\hline
\end{tabular}

Ropel et al., 2005). The $K_{\text {ow }}$ is defined as the ratio of the equilibrium concentrations of a dissolved substance in a two-phase octanol and water system, and is expressed by the following equation (Sangster, 1989):

$K_{\text {ow }}=\frac{[\text { solute }]_{\text {octanol }}}{[\text { solute }]_{\text {water }}}$

The octanol-water partition coefficients of the ampicillin-based ionic liquids, as well as the starting L-ampicillin and ampicillin sodium salt were determined by the shake flask method (OECD, 1993) as previously described, and the results are shown in Table 3 and plotted in Fig. 2. Only one literature value was obtained for ampicillin octanol-water partition coefficient (Hollosy et al., 2006). The difference between the result presented by these authors, 0.050 , and that obtained in the present work, 0.020 , is most probably due to the different experimental methods used. Hollosy et al. (2006) used a chromatographic retention method to measure the extent of the partition between the mobile and the stationary phase. The binding constants were derived from retention time measurements.

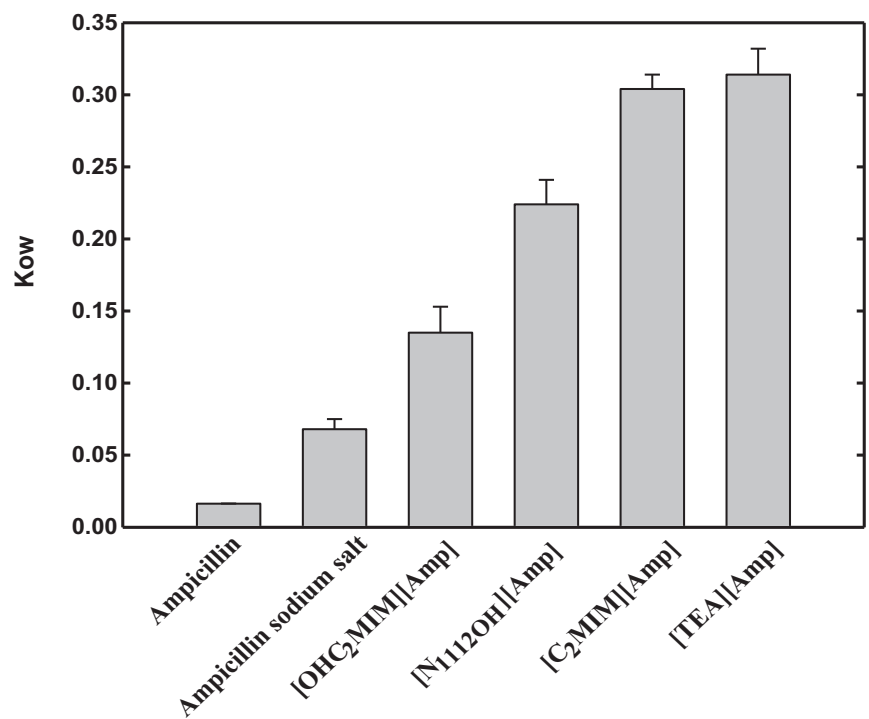

Fig. 2. Octanol-water partition coefficient of L-ampicillin, ampicillin sodium salt and ampicillin-based ILs at $25^{\circ} \mathrm{C}$, determined by the shake flask method.
According Fig. 2, the effect of using the ionic liquids synthetic platform in the octanol-water partition coefficients can be easily disclosed. All the ampicillin-based ILs have a higher value of $K_{\text {ow }}$ than ampicillin. As expected, the more hydrophilic ionic liquids, [ $\left.\mathrm{C}_{2} \mathrm{OHMIM}\right][\mathrm{Amp}]$ and $\left[\mathrm{N}_{1112 \mathrm{OH}}\right]\left[\right.$ Amp], display lower $K_{\mathrm{ow}}$ 's than the more hydrophobic, [ $\left.\mathrm{C}_{2} \mathrm{MIM}\right][$ Amp] and [TEA][Amp]. Nevertheless, despite the enhancement of the water solubility of [C $\left.\mathrm{C}_{2} \mathrm{OHMIM}\right][\mathrm{Amp}],\left[\mathrm{N}_{1112 \mathrm{OH}}\right][\mathrm{Amp}]$ and [ $\left.\mathrm{C}_{2} \mathrm{MIM}\right][\mathrm{Amp}]$, there is also an increase in the $K_{\text {ow }}$ values. This fact indicates that not only the water solubility of these ampicillin-based ILs was enhanced, but also the "n-octanol solubility", that is the affinity for the organic phase was also increased. The relationship between the ampicillinbased ILs water solubility and the $K_{\text {ow }}$ values at $25^{\circ} \mathrm{C}$ is depicted in Fig. 3. As expected, the API-IL that has the highest solubility in water

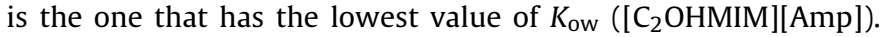
On the other hand, [TEA][Amp] presents the lowest water solubility values and thus the highest values of $K_{\text {ow }}$. Based on Fig. 3 it is possible to evaluate relationship between water solubility and the octanol-water partition coefficient, so that the best API-IL can be chosen from a pharmaceutical and therapeutical point of view. For the ampicillin sodium salt the octanol-water partition coefficient was also determined at $25^{\circ} \mathrm{C}$ (Table 3 ). The comparison of the two sets of results, aqueous solubility and octanol-water partition coefficient, for both ampicillin sodium salt and ampicillin-based ILs (Fig. 3 ) reveals that the IL approach is much more versatile than the "traditional salt" approach, allowing simultaneously the enhancement of the aqueous solubility and the octanol-water partition coefficient.

\subsection{HDPC-water partition coefficient}

Spectra derivative is a wide spread method useful to eliminate baseline interferences, enhance spectral features and separate overlapping bands when using spectroscopy. In this work, it

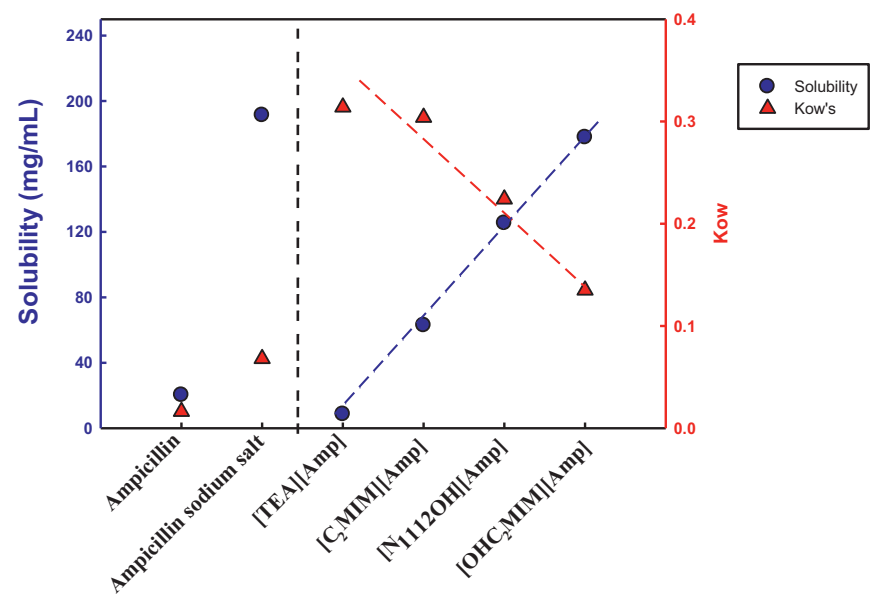

Fig. 3. Comparative analysis between the aqueous solubility $(\bullet)$ and octanol-water partition coefficient $(\boldsymbol{\Lambda})$ of L-ampicillin, ampicillin sodium salt and ampicillin-based ILs at $25^{\circ} \mathrm{C}$. 


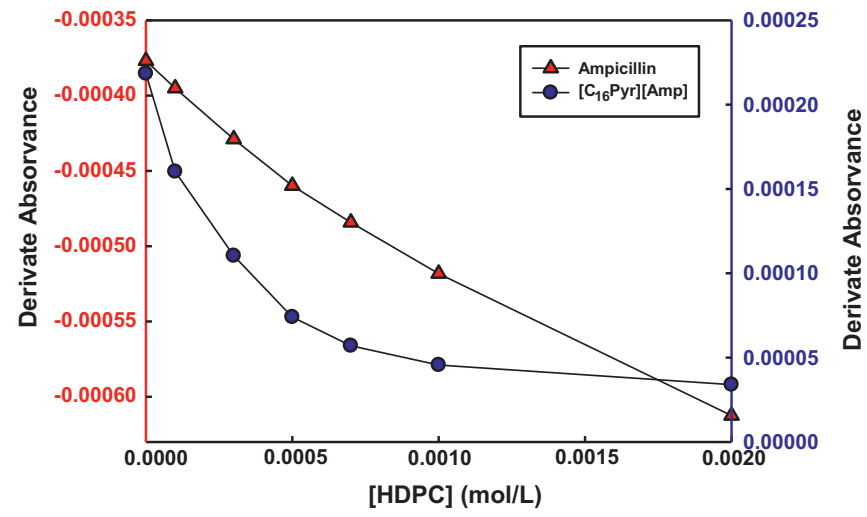

Fig. 4. Second-derivative spectrophotometric data at $\lambda=300 \mathrm{~nm}$ for L-ampicillin (triangles) and at $\lambda=284 \mathrm{~nm}$ for [ $\left.\mathrm{C}_{16} \mathrm{Pyr}\right][\mathrm{Amp}]$ (circles) in different concentrations of HDPC. The curve represents the best fit by a non-linear regression method, that allows determination of HDPC-water partition coefficients $\left(K_{\mathrm{p}}\right)$.

Table 4

HDPC-water partition coefficients $\left(K_{\mathrm{p}}\right)$ of ampicillin-based ILs (mean and standard deviation) at $25^{\circ} \mathrm{C}$.

\begin{tabular}{lc}
\hline API/API-ILs & $K_{\mathrm{p}}$ \\
\hline L-Ampicillin & $384 \pm 95$ \\
{$[$ TEA][Amp] } & $910 \pm 263$ \\
{$\left[\mathrm{~N}_{1112 \mathrm{OH}][\text { Amp }]}\right.$} & $1130 \pm 256$ \\
{$\left[\mathrm{C}_{16}\right.$ Pyr][Amp] } & $4715 \pm 1297$ \\
{$\left[\mathrm{P}_{6,6,6,14}\right][$ Amp $]$} & $4772 \pm 1488$ \\
\hline
\end{tabular}

allowed the detection of small spectral variations due to the interaction of the drugs with the micelles. In the case of the "blanks", which presents light scattering due to the presence of the micelles, rather than absorption, spectra derivative originated signal zeroing. Data points from the drug spectra were collected at wavelengths were this zeroing was effective. HDPC-water partition coefficients $\left(K_{\mathrm{p}}\right)$ were then calculated by a nonlinear fitting method (Castro et al., 2001). Examples of fitting are presented in Fig. 4, and the results obtained assembled in Table 4. It was not possible to determine $K_{\mathrm{p}}$ values for [ $\left.\mathrm{C}_{2} \mathrm{MIM}\right][\mathrm{Amp}]$ and [ $\left.\mathrm{C}_{2} \mathrm{OHMIM}\right][\mathrm{Amp}]$ because these salts did not present an adequate spectral change when interacting with the micelles.

L-Ampicillin is an amphoteric drug showing a $\mathrm{p} K_{\mathrm{a}}$ of 2.5 from carboxylic group and $\mathrm{p} K_{\mathrm{a}}$ of 7.3 from amine group. Subsequently, at the physiologic $\mathrm{pH}(7.4)$ the acidic group will present a negative charge, with $44 \%$ of the molecules being zwitterionic. This makes the L-ampicillin molecule not ready to interact with the biological membranes, since the hydrophilicity and hydration of large ions difficult the passive diffusion through the phospholipid core. The association of L-ampicillin with a positive ion, such as those used here, form an ion pair and decreases the global molecular charge, which favors the intercalation of the drugs molecule between the HDPC carbonated tails. For this reason, the $K_{\mathrm{p}}$ values obtained for the API-ILs studied were substantially larger than the result for ampicillin, and even larger in the case of [ $\left.\mathrm{C}_{16} \mathrm{Pyr}\right][\mathrm{Amp}]$ and $\left[\mathrm{P}_{6,6,6,14}\right][\mathrm{Amp}]$, because these molecules present a higher amphiphilic behavior.

\subsection{Critical micelle concentrations}

The evaluation of micelle formation in drugs is essential for the assessment of their properties and their influence on biological processes (Leo et al., 1971). The study of the combination of an API with an ionic liquid possessing surfactant activity is attractive because novel therapies using surfactant API-ILs can be envisaged (Bernardes et al., 2011). Accordingly, assays to determine
Table 5

Critical micelle concentrations (CMC's) of the surfactant ampicillin-based ILs calculated from conductivity measurements at $25^{\circ} \mathrm{C}$ and $37^{\circ} \mathrm{C}$. The CMC's of chloride-based ILs with the same organic cations measured in this work are also listed.

\begin{tabular}{lll}
\hline Surfactant ILs & $\begin{array}{l}\mathrm{CMC} \text { at } 25^{\circ} \mathrm{C} \\
\left(\mathrm{mmol} \mathrm{L}^{-1}\right)\end{array}$ & $\begin{array}{l}\mathrm{CMC} \text { at } 37^{\circ} \mathrm{C} \\
\left(\mathrm{mmol} \mathrm{L}^{-1}\right)\end{array}$ \\
\hline$\left[\mathrm{C}_{16} \mathrm{Pyr}\right][\mathrm{Amp}]$ & 0.444 & 0.478 \\
{$\left[\mathrm{C}_{16} \mathrm{Pyr}\right] \mathrm{Cl}$} & $1.063(1.067$ (Wang et al., 1999)) & 1.026 \\
{$\left[\mathrm{P}_{6,6,6,14}\right][\mathrm{Amp}]$} & 0.358 & 0.336 \\
{$\left[\mathrm{P}_{6,6,6,14}\right] \mathrm{Cl}$} & $0.531(0.77$ (Bakshi and Kaur, 2006)) & 0.522 \\
\hline
\end{tabular}

the critical micelle concentrations (CMC's) of the pharmaceutical ampicillin-based ILs bearing cations with surfactant properties, in water at $25^{\circ} \mathrm{C}$ and $37^{\circ} \mathrm{C}$ were performed.

The ampicillin-based ILs with surfactant properties proposed in the present study are the cetylpyridinium ampicillin ([ $\left.\left.\mathrm{C}_{16} \mathrm{Pyr}\right][\mathrm{Amp}]\right)$ and the trihexyltetradecylphosphonium ampicillin $\left(\left[\mathrm{P}_{6,6,6,14}\right][\mathrm{Amp}]\right)$. Please note that it is not possible to measured water solubility and octanol-water partition coefficients for these two surfactants. In this way, only CMC's values were measured.

Two ILs with similar cations, $\left[\mathrm{P}_{6,6,6,14}\right] \mathrm{Cl}$ and $\left[\mathrm{C}_{16} \mathrm{Pyr}\right] \mathrm{Cl}$, were used to validate the experimental procedure in the determination of the critical micelle concentration, previously described. The implemented procedure is based on measurements of the ionic conductivities of aqueous solutions with different ILs concentrations. This conductivity method is grounded on the accurate determination of a breaking point on description of the conductivity of the solution in terms of the concentration of the surfactant in the solution and consequently a significant change in the slope of the linear line. It is well-known, that the conductivity of a solution is directly proportional to the concentration of its ions. The conductivity curves for both ampicillin-based ILs at $25^{\circ} \mathrm{C}$ are presented in Supporting Information. The values obtained for the ionic conductivities are listed in Supporting Information and the CMC values, determined at the two different working temperatures $\left(25^{\circ} \mathrm{C}\right.$ and $37^{\circ} \mathrm{C}$ ), are presented in Table 5 along with literature values (Wang et al., 1999; Bakshi and Kaur, 2006). In both literature sources, CMCs were measured using fluorescence.

Negligible differences in the CMC's were found, when comparing both studied temperatures. The CMC values determined for the same compound at different temperatures showed deviations below $5 \%$, which is within the experimental error of the implemented method.

From the analysis of Table 5 , it is possible to discuss the differences in the values obtained for the ILs that have the same surfactant cation combined with different counter-ions. For both the cations, $\left[\mathrm{C}_{16} \mathrm{Pyr}\right]^{+}$and $\left[\mathrm{P}_{6,6,6,14}\right]^{+}$, the results show that when the chloride anion is considered, the CMC values are always higher than those obtained for the same cation paired with the ampicillin anion. These results were expected, since the smaller the size of the anion, the higher its degree of hydration, making the process of micelle formation more difficult, and thus higher values of CMC are obtained (Rangel-Yagui et al., 2005). The less hydrated ions can be adsorbed easily on the micellar surfaces, and decrease the charge repulsion between the polar groups. This mechanism leads to the formation of larger micelles. Another factor that influences the CMC values is the nature of the anion (Kilikian et al., 2000).

Anions with organic nature such as ampicillin decrease the value of CMC when compared to anions of inorganic nature (e.g. chloride). Regarding the effect of the cation, it is possible to verify that the two ampicillin-based ionic liquids have similar values of CMC. However, $\left[\mathrm{P}_{6,6,6,14}\right]\left[\right.$ Amp] presents a lower $\mathrm{CMC}$ value than $\left[\mathrm{C}_{16}\right.$ Pyr][Amp]. The same behavior was found for $\left[\mathrm{P}_{6,6,6,14}\right] \mathrm{Cl}$ and $\left[\mathrm{C}_{16} \mathrm{Pyr}\right] \mathrm{Cl}$. The determining factor for this difference is the hydrophobicity of the 
cation, which can be considered by the number of carbons present in the alkyl side-chain. The greater the number of carbon atoms in non polar chain, the smaller the value of its CMC.

\section{Conclusion}

This work focuses the evaluation of relevant pharmacological properties such as water solubility, octanol-water partition coefficient, HDPC-water partition coefficient and critical micelle concentration of novel ampicillin-based pharmaceutical active ionic liquids. The disclosed results clearly confirm the great potential of the API-IL methodology, since ampicillin-based ILs with enhanced properties regarding solubility in water, as well as more adequate properties regarding membrane affinity and permeation were reported. The accurate selection of the organic cation allows the fine-tuning of some important physical and thermal properties, such as water solubility, membrane permeation, melting point and thermal stability. [ $\left.\mathrm{N}_{1112 \mathrm{OH}}\right][$ Amp] is the most interesting of the prepared active pharmaceutical ILs, as a result of its properties low melting point, enhanced aqueous solubility and octanol-water partition coefficient relatively to the starting ampicillin, plus the biocompatibility and low toxicity of the choline cation. Therefore, it will probably be the most interesting ampicillin-based ILs in further medicinal investigations. Additionally, ampicillin-based ILs with surfactant properties were developed and characterized for potential applications in drug delivery. The results here obtained offer new and interesting avenues of research for both pharmaceutical and ionic liquids communities.

\section{Acknowledgments}

The financial support from Fundação para a Ciência e Tecnologia - FCT (Portugal), through grant SFRH/BPD/65981/2009 (J.M.M. Araújo) and two contracts under Programa Ciência 2007 (I.M. Marrucho and L.C. Branco). Project PTDC/EQU-EPR/104554/2008 and PTDC/EQU-FTT/116015/2009 is gratefully acknowledged. The NMR spectrometers are part of the National NMR Network (RNRMN) and are funded by FCT. The authors gratefully Cytec Industries Research for supplying trihexyl(tetradecyl)phosphonium chloride and Solchemar for supplying 1-ethyl-3-methylimidazolium bromide and 1-hydroxy-ethyl-3-methylimidazolium chloride.

\section{Appendix A. Supplementary data}

Supplementary data associated with this article can be found, in the online version, at http://dx.doi.org/10.1016/j.ijpharm.2013. 08.010 .

\section{References}

Alves, F., Oliveira, F.S., Schroder, B., Matos, C., Marrucho, I.M., 2013. Synthesis, characterization, and liposome partition of a novel tetracycline derivative using the ionic liquids framework. J. Pharm. Sci. 102, 1504-1512.

Bakshi, M.S., Kaur, G., 2006. Mixed micelle behavior of poly(ethylene glycol) alkyl ethers with series of monomeric cationic, phosphonium cationic, and zwitterionic surfactant. Colloid Polym. Sci. 285, 101-106.

Bennett, B., Cole, G., 2003. Pharmaceutical Production - An Engineering Guide. IChemE.

Bernardes, C.E.S., da Piedade, M.E.M., Lopes, J.N.C., 2011. The structure of aqueous solutions of a hydrophilic ionic liquid: the full concentration range of 1-ethyl-3methylinnidazolium ethylsulfate and water. J. Phys. Chem. B 115, 2067-2074.

Bica, K., Rijksen, C., Nieuwenhuyzen, M., Rogers, R.D., 2010. In search of pure liq uid salt forms of aspirin: ionic liquid approaches with acetylsalicylic acid and salicylic acid. Phys. Chem. Chem. Phys. 12, 2011-2017.

Bica, K., Rodriguez, H., Gurau, G., Cojocaru, O.A., Riisager, A., Fehrmann, R., Rogers, R.D., 2012. Pharmaceutically active ionic liquids with solids handling, enhanced thermal stability, and fast release. Chem. Commun. 48, 5422-5424.
Blesic, M., Lopes, J.N.C., Gomes, M.F.C., Rebelo, L.P.N., 2010. Solubility of alkanes, alkanols and their fluorinated counterparts in tetraalkylphosphonium ionic liquids. Phys. Chem. Chem. Phys. 12, 9685-9692.

Byrn, S.R., Pfeiffer, R.R., Stowell, J.G., 1999. Solid-state Chemistry of Drugs. SSCI, West Lafayette.

Castro, B., Gameiro, P., Lima, J.L.F.C., Matos, C., Reis, S., 2001. Interaction of drugs with hexadecylphosphocholine micelles. Derivative spectroscopy, acidbase and solubility studies. Mater. Sci. Eng. C-Biomimetic Supramol. Syst. 18, 71-78.

Costa, A.J.L., Soromenho, M.R.C., Shimizu, K., Marrucho, I.M., Esperanca, J.M.S.S., Lopes, J.N.C., Rebelo, L.P.N., 2012. Density, thermal expansion and viscosity of cholinium-derived ionic liquids. ChemPhysChem 13, 1902-1909.

Cybulski, J., Wisniewska, A., Kulig-Adamiak, A., Dabrowski, Z., Praczyk, T., Michalczyk, A., Walkiewicz, F., Materna, K., Pernak, J., 2011. Mandelate and prolinate ionic liquids: synthesis, characterization, catalytic and biological activity. Tetrahedron Lett. 52, 1325-1328.

Dean, P.M., Turanjanin, J., Yoshizawa-Fujita, M., MacFarlane, D.R., Scott, J.L. 2009. Exploring an anti-crystal engineering approach to the preparation of pharmaceutically active ionic liquids. Cryst. Growth Des. 9, 1137-1145

Ferraz, R., Branco, L.C., Marrucho, I.M., Araujo, J.M.M., Rebelo, L.P.N., da Ponte, M.N. Prudencio, C., Noronha, J.P., Petrovski, Z., 2012. Development of novel ionic liquids based on ampicillin. MedChemComm 3, 494-497.

Ferraz, R., Branco, L.C., Prudêncio, C., Noronha, J.P., Petrovski, Z., 2011. Ionic liquids as active pharmaceutical ingredients. ChemMedChem 6, 975-985.

Ferreira, H., Lucio, M., Lima, J.L.F.C., Matos, C., Reis, S., 2005. Effects of diclofenac on EPC liposome membrane properties. Anal. Bioanal. Chem. 382, 1256-1264.

Hansch, C., Dunn, W.J., 1972. Linear relationships between lipophilic character and biological-activity of drugs. J. Pharm. Sci. 61, 1-19.

Hollosy, F., Valko, K., Hersey, A., Nunhuck, S., Keri, G., Bevan, C., 2006. Estimation of volume of distribution in humans from high throughput HPLC-based measurements of human serum albumin binding and immobilized artificial membrane partitioning. J. Med. Chem. 49, 6958-6971.

Hough-Troutman, W.L., Smiglak, M., Griffin, S., Reichert, W.M., Mirska, I., JodynisLiebert, J., Adamska, T., Nawrot, J., Stasiewicz, M., Rogers, R.D., Pernak, J., 2009. Ionic liquids with dual biological function: sweet and anti-microbial, hydrophobic quaternary ammonium-based salts. New J. Chem. 33, 26-33.

Hough, W.L., Smiglak, M., Rodriguez, H., Swatloski, R.P., Spear, S.K., Daly, D.T., Pernak J., Grisel, J.E., Carliss, R.D., Soutullo, M.D., Davis, J.H., Rogers, R.D., 2007. The third evolution of ionic liquids: active pharmaceutical ingredients. New J. Chem. 31 1429-1436.

Kilikian, B.V., Bastazin, M.R., Minami, N.M., Goncalves, E.M.R., Pessoa, A., 2000. Liquid-liquid extraction by reversed micelles in biotechnological processes. Braz. J. Chem. Eng. 17, 29-38.

Leo, A., Hansch, C., Elkins, D., 1971. Partition coefficients and their uses. Chem. Rev 71, 525-552.

Liu, C.L., Chang, T.C., Wu, S.M., Chiang, H.J., 2006. Total solubility determination of mixtures containing ampicillin anhydrate and ampicillin trihydrate. J. Chin. Chem. Soc. 53, 851-856.

Marcelino, J., Lima, J.L.F.C., Reis, S., Matos, C., 2007. Assessing the effects of surfactants on the physical properties of liposome membranes. Chem. Phys. Lipids 146, 94-103.

OECD, 1993. OECD Guideline for the Testing of Chemicals: 107 Partition Coefficient (n-Octanol/water): Shake Flask Method, Paris.

Rangel-Yagui, C.O., Pessoa, A., Tavares, L.C., 2005. Micellar solubilization of drugs. J. Pharm. Pharm. Sci. 8, 147-163.

Rogers, R.D., Seddon, K.R., 2005. In: Rogers, R., et al. (Eds.), Ionic Liquids IIIA: Fundamentals, Progress, Challenges and Opportunities; ACS Symposium Series. American Chemical Society, Washington, DC

Ropel, L., Belveze, L.S., Aki, S.N.V.K., Stadtherr, M.A., Brennecke, J.F., 2005. Octanol-water partition coefficients of imidazolium-based ionic liquids. Green Chem. 7, 83-90

Sangster, J., 1989. Octanol-water partition-coefficients of simple organiccompounds. J. Phys. Chem. Ref. Data 18, 1111-1229.

Smiglak, M., Reichert, W.M., Holbrey, J.D., Wilkes, J.S., Sun, L.Y., Thrasher, J.S., Kirichenko, K., Singh, S., Katritzky, A.R., Rogers, R.D., 2006. Combustible ionic liquids by design: is laboratory safety another ionic liquid myth? Chem. Commun. 2554-2556.

Stoimenovski, J., Dean, P.M., Izgorodina, E.I., MacFarlane, D.R., 2012. Protic pharmaceutical ionic liquids and solids: aspects of protonics. Faraday Discuss. 154 335-352.

Stoimenovski, J., MacFarlane, D.R., 2011. Enhanced membrane transport of pharmaceutically active protic ionic liquids. Chem. Commun. 47, 11429-11431.

Stoimenovski, J., MacFarlane, D.R., Bica, K., Rogers, R.D., 2010. Crystalline vs. ionic liquid salt forms of active pharmaceutical ingredients: a position paper. Pharm. Res. 27, 521-526.

Variankaval, N., Cote, A.S., Doherty, M.F., 2008. From form to function: crystallization of active pharmaceutical ingredients. AIChE J. 54, 1682-1688.

Wang, K., Karlsson, G., Almgren, M., Asakawa, T., 1999. Aggregation behavior of cationic fluorosurfactants in water and salt solutions. A cryoTEM survey. J. Phys. Chem. B 103, 9237-9246.

Wasserscheid, P., Welton, T., 2002. Ionic Liquids in Synthesis 